\title{
Hidroxiapatita e quitosana isoladas e associadas à medula óssea no reparo do tecido ósseo em coelhos. Estudo histológico e morfométrico
}

\author{
Hydroxyapatite and chitosan isolated and associated with bone marrow in repair \\ of bone tissue in rabbits. Histological and morfometric study
}

\begin{abstract}
Adílio Santos de Azevedo ${ }^{\mathrm{I}^{*}}$ Marcelo Jorge Cavalcanti de Sá ${ }^{\mathrm{I}}$ Marcus Vinícius Lia Fook Pedro Isidro da Nóbrega Neto ${ }^{\mathrm{I}}$ Otávio Brilhante de Sousa ${ }^{\mathrm{I}}$ Sérgio Santos de Azevedo ${ }^{\mathrm{I}}$
\end{abstract}

RESUMO

O objetivo do presente trabalho foi avaliar o processo de regeneração óssea em coelhos através da utilização da hidroxiapatita e da quitosana isoladas e associadas à medula óssea. Foram utilizados 20 coelhos adultos, de ambos os sexos, da raça Nova Zelândia e pesando em média $3,0 \pm 0,4 \mathrm{~kg}$. Os animais foram divididos ao acaso de acordo com dois momentos experimentais, sendo que 10 animais foram submetidos à eutanásia 30 dias após a cirurgia, e 10, 60 dias após a cirurgia. Foram utilizados quatro implantes que constituíram os grupos. Os materiais foram introduzidos em defeitos criados cirurgicamente na metáfise proximal (MP) e distal (MD) de cada fêmur, de modo que a quitosana foi introduzida na MP e a hidroxiapatita na MD do membro esquerdo e, no membro direito, além dos implantes, foi adicionada medula óssea. Na avaliação histológica descritiva comparativa, constatou-se que os grupos QUI e QUIMO, em ambos os momentos estudados, estimularam reações mais acentuadas $e$ aceleraram o reparo ósseo. Na análise morfométrica, os grupos QUI e QUIMO diferiram estatisticamente dos outros grupos, tendo sido observada maior formação óssea $(P<0,05)$.

Palavras-chave: biomateriais, biopolímero, cicatrização óssea, fosfatos de cálcio.

\section{ABSTRACT}

The aim of this research was to evaluate the process of bone regeneration in rabbits by the use of hydroxyapatite and chitosan only and associated with bone marrow. Twenty male and female rabbits, New Zealand breed and weighing in average $3.0 \pm 0.4 \mathrm{~kg}$ were used. Animals were randomly divided according with two experimental moments, being 10 animals euthanized 30 days after surgery, and 10 euthanized 60 days after surgery. Four implants that constituted the groups were used. Materials were introduced into the proximal (MP) and distal metaphysis (MD) of each femur, so that chitosan was introduced into the MP and hydroxyapatite into the MD of the left limb, and in the right limb bone marrow was added beyond the implants. At the comparative descriptive histological evaluation, it was found that the QUI and QUIMO groups in both periods stimulated more pronounced reactions and accelerated bone repair. In morphometric analysis, QUI and QUIMO groups differed statistically from the other, has been shown greater bone formation $(P<0.05)$.

Key words: biomaterials, biopolymer, bone healing, calcium bhosphate.

\section{INTRODUÇÃO}

Vários são os biomateriais desenvolvidos e aplicados em modelos animais para obtenção de uma regeneração óssea mais rápida, tais como os cimentos de fosfato de cálcio e os biopolímeros (KHOR \& LIM, 2003; AZEVEDO et al., 2012). Dentre os cimentos de fosfatos de cálcio mais utilizados em cirurgias óssea, a hidroxiapatita é a que apresenta maior destaque, pois apresenta formulação físico-química semelhante à do osso, possibilitando assim substrato para que ocorra o processo de osteocondução (LEGEROS, 2002).

A quitosana é extraída da quitina, que é um dos biopolímeros mais abundantes na natureza e vem ganhando destaque em pesquisas médicas nos últimos anos, por sua possível capacidade reparadora tecidual

'Unidade Acadêmica de Medicina Veterinária (UAMV), Centro de Saúde e Tecnologia Rural (CSTR), Universidade Federal de Campina Grande (UFCG), Av. Universitária s/n, Bairro Santa Cecília, 58700-970, Patos, PB, Brasil. E-mail: adílio_vet@yahoo.com.br. *Autor para correspondência.

"Unidade Acadêmica de Engenharia de Materiais (UAEM), UFCG, Campina Grande, PB, Brasil. 
(KHAN \& PEH, 2003; AZEVEDO et al., 2007). Apresenta-se como um material biocompatível, atóxico e biodegradável (GE et al., 2004). Experimentos realizados apontam que a quitosana tem capacidade de favorecer neoformação óssea por estimular a liberação de citocinas, favorecendo a angiogênese e osteogênese (MUZZARELI et al., 1994; UENO et al., 2001; WANG et al., 2002; GORZELANNY et al., 2010).

A medula óssea (MO) é o principal órgão hematopoiético nos animais e no homem, apresentando várias linhagens celulares que a compõem. Dentre essas células, estão incluídas as células-tronco multipotentes, conhecidas também como mesenquimatosas, responsáveis pela origem de vários tipos celulares. Essas células apresentam-se em repouso, sendo ativadas pelos estímulos ambientais e humorais inerentes dos tecidos e dos fatores de crescimento (DOSS et al., 2004). KRZYMANSKI et al. (1997) evidenciaram que a utilização de MO diretamente na lesão favoreceu a cicatrização mais rápida do defeito ósseo. Vem sendo crescente a associação dos biomateriais a células da medula óssea, com o objetivo de se obter a citodiferenciação das células tronco em osteoblastos e assim ocorrer a formação mais rápida do calo ósseo (ABUKAWA, 2003; SHIMAKURA et al., 2003).

Devido à busca constante de materiais e procedimentos que possam acelerar o processo de regeneração óssea com o mínimo de efeitos indesejáveis nos pacientes, o presente trabalho teve como objetivo avaliar o processo de regeneração óssea em coelhos através da utilização da hidroxiapatita e da quitosana isoladas e associadas a MO, observando qual dos tratamentos empregados estimula uma maior e mais rápida neoformação óssea.

\section{MATERIAL E MÉTODOS}

Neste experimento, utilizaram-se 20 coelhos adultos, de ambos os sexos, da raça Nova Zelândia, pesando em média $3,0 \pm 0,4 \mathrm{~kg}$, provenientes de um criatório situado na cidade de Campina Grande - PB. Os animais foram separados ao acaso em dois momentos experimentais, com 10 animais cada momento, de acordo com o período de eutanásia (30 ou 60 dias após o procedimento cirúrgico). Os animais foram alocados em gaiolas individuais, vermifugados com albendazol ${ }^{\mathrm{a}} 5 \%$ na dose de $20 \mathrm{mg} \mathrm{kg}^{-1}$ por via oral e passaram por um período de adaptação de sete dias antes do início do experimento, recebendo ração balanceada duas vezes ao dia e água potável ad libitum durante todo o experimento.

Os tratamentos utilizados e a aplicação dos implantes foram distribuídos da seguinte forma: quitosana (QUI) na metáfise proximal e hidroxiapatita de razão 1,67 (HA) na metáfise distal, ambas no fêmur esquerdo. No fêmur direito, além dos implantes introduzidos na mesma posição utilizada no fêmur esquerdo, ainda foi acrescido $0,25 \mathrm{~mL}$ de $\mathrm{MO}$ cobrindo a interface osso/implante, obtida do trocanter maior do fêmur direito. Após a tricotomia, realizou-se a medicação pré-anestésica com acepromazina ${ }^{\mathrm{b}}$, na dose de $1 \mathrm{mg} \mathrm{kg}^{-1}$ por via intravenosa (IV) e anestesia com zoletil ${ }^{\mathrm{c}}$ na dose de $15 \mathrm{mg} \mathrm{kg}^{-1} \mathrm{IV}$. Após antissepsia da área operatória com solução de clorexidine ${ }^{\mathrm{d}}$ a $0,5 \%$, fez-se uma incisão cutânea ao longo da margem craniolateral da diáfise femoral e divulsão do tecido subcutâneo e muscular. Foi feita ressecção longitudinal do periósteo e dois orifícios foram construídos, um na metáfise proximal e outro na distal, com broca cirúrgica de 2,0mm de diâmetro para colocação dos implantes. Após a introdução dos implantes, foi realizada a síntese dos tecidos. Esse procedimento foi realizado nos dois membros pélvicos.

No pós-operatório, os animais receberam enrofloxacina $^{\mathrm{e}}$ na dose de $10 \mathrm{mg} \mathrm{kg}^{-1}$ por via intramuscular (IM) uma vez ao dia durante 5 dias e meloxicam $^{\mathrm{f}}$ na dose de $0,2 \mathrm{mg} \mathrm{kg}^{-1} \mathrm{IM}$ no primeiro dia (fármaco administrado 30 minutos antes do procedimento cirúrgico) e $0,1 \mathrm{mg} \mathrm{kg}^{-1}$ nos dois dias subsequentes. Também foi administrado, em todos os animais, tramadolg na dose de $1 \mathrm{mg} \mathrm{kg}^{-1} \mathrm{IM}$, antes do procedimento operatório. A higienização da ferida cirúrgica foi realizada com solução fisiológica e kuraderm prata ${ }^{\mathrm{h}}$ durante os 10 primeiros dias do pósoperatório, tendo sido retiradas as suturas após esse período.

Os animais foram submetidos à eutanásia ao final do período de observação destinado a cada momento, tendo sido colhido os fragmentos do tecido ósseo que continham os implantes. Os fragmentos ósseos foram fixados em formalina tamponada a $10 \%$ durante 10 dias e descalcificados em mistura de partes iguais de solução de ácido fórmico 5\%+ ácido clorídrico 5\% durante 14 dias. Os fragmentos foram incluídos em parafina líquida e posteriormente cortados em fatias transversais de $5 \mu \mathrm{m}$ de espessura 
dos blocos e montados em lâminas histológicas. De cada bloco, foram obtidas quatro lâminas, sendo estas submetidas às técnicas de hematoxilinaeosina para visualização histológica, avaliando-se a interface osso-implante, os graus de reação endosteal e periosteal, proliferação e diferenciação celular no tecido cicatricial, presença de tecido conjuntivo e cicatrização óssea da lesão. Nessa análise, foi realizada avaliação descritiva qualitativa e comparação entre os momentos e grupos.

A neoformação óssea induzida pelos tratamentos foi quantificada através da análise morfométrica das lâminas, através do programa Image Pro Plus, versão 6.2 ${ }^{\circledR}$. Para essa análise, foram realizadas capturas e digitalização das imagens que compreenderam a interface osso/implante. Foram obtidas imagens sequenciadas de cada lâmina analisada para quantificar em $\mu \mathrm{m}^{2}$ todo o tecido ósseo neoformado em toda interface osso/implante. Foi obtida a média dos valores para cada grupo estudado e submetidos à análise estatística.

A comparação da cicatrização óssea induzida pelos tratamentos foi realizada por momento experimental e entre os grupos. Inicialmente, foi realizado o teste de normalidade de Anderson-Darling para a verificação da distribuição dos dados. Para variáveis com distribuição normal, os grupos foram comparados pela análise de variância (ANOVA) de um critério de classificação, com comparações múltiplas pelo teste de Tukey. Para variáveis com distribuição não normal, a comparação foi realizada pelo teste não-paramétrico de Kruskal-Wallis, com comparações múltiplas pelo teste de Nemenyi (ZAR, 1999). O nível de significância adotado foi de $5 \%$ e as análises foram feitas com o programa estatístico MINITAB, versão 14.0.

\section{RESULTADOS}

$\mathrm{Na}$ avaliação histológica, pôde-se observar, aos 30 dias de pós-operatório, na interface osso-implante que recebeu a quitosana, endósteo e periósteo irregular com reação celular intensa, muitos osteoblastos e osteoclastos ativos, grande quantidade de fibroblastos e tecido conjuntivo, intensa neoformação vascular, tecido ósseo imaturo em volta de todo o implante com cicatrização avançada da lesão e presença de células mesenquimais em processo de diferenciação. A interface preenchida pela associação de quitosana e medula óssea apresentava-se com as mesmas reações observadas com a quitosana isolada, porém havia maior quantidade de células mesenquimais em processo de diferenciação. Já na interface que recebeu a HA, observou-se endósteo e periósteo bem regulares com presença de pouca celularidade, pequena atividade osteblástica e osteoclástica, presença de pequena quantidade de fibroblastos com pouca deposição de tecido conjuntivo, pouca neoformação vascular e menos tecido ósseo neoformado em comparação com o grupo QUI e QUIMO. Na avaliação da lesão óssea que foi preenchida pela HA, associada à medula óssea, observaram-se as mesmas reações encontradas na HA isolada, porém havia maior quantidade de fibroblastos e fibras colágenas, neovascularização e neoformação óssea, comparado ao grupo HA.

Nos animais submetidos a eutanásia aos 60 dias de pós-operatório, na interface osso-implante que recebeu a quitosana, foi observado que o periósteo apresentava-se menos irregular em relação aos 30 dias, os osteoclastos estavam em maior quantidade, com muito tecido ósseo neoformado em volta de todo o implante e presença de células mesenquimais em diferenciação. A interface preenchida pela associação de quitosana e medula óssea permanecia com intensa atividade celular e a cicatrização da lesão óssea encontrava-se avançada com muito tecido ósseo neoformado em volta do implante, presença de células mesenquimais indiferenciadas em atividade. $\mathrm{Na}$ interface que recebeu a HA, observou-se que as reações permaneciam muito discretas. $\mathrm{Na}$ associação da HA à medula óssea, observou-se regularidade endosteal e periosteal com pouca celularidade, pouca quantidade de osteoblastos, porém os osteoclastos estavam em maior quantidade, comparado ao grupo HAMO 30 dias.

$\mathrm{Na}$ avaliação morfométrica das lâminas, observou-se que tanto aos 30 quanto aos 60 dias os grupos QUI e QUIMO induziram neoformação óssea maior que os demais implantes.

\section{DISCUSSÃO}

$\mathrm{Na}$ avaliação histológica descritiva comparativa, observou-se que os grupos QUI e QUIMO, em ambos os momentos estudados, estimularam reações mais acentuadas que os grupos comparados. Esse fato é explicado pelas características da quitosana, que é um polissacarídeo catiônico que apresenta estrutura semelhante aos 
glicosaminoglicanos, os quais se apresentam como principais componentes da matriz extracelular de cartilagens e ossos. Além disso, a quitosana atua atraindo íons cálcio, favorecendo dessa forma o processo de cicatrização óssea (KHOR \& LIM, 2003). Esse biopolímero, após ser desacetilado, tem a capacidade de ativar os macrófagos, que liberam IL6 e IL8 e outros fatores de crescimento, promovendo a cicatrização dos tecidos (UENO et al., 2001; GORZELANNY et al., 2010). Dessa forma, evidenciou-se, no presente estudo, que a quitosana acelerou e maximizou o reparo ósseo, apresentando grande potencial osteogênico, atuando como um biomaterial osteoindutor, processo esse também observado no trabalho de GE et al. (2004).

Em relação à implantação da HA isolada e associada à medula óssea durante o tempo experimental, foi evidenciado que o tecido ósseo neoformado por esses dois tratamentos foi discreto comparado aos outros grupos, fato esse explicado pela capacidade desse biomaterial de estimular apenas a osteocondução (LOPES, 1999; LEGEROS, 2002), diferentemente da quitosana, que estimula a citodiferenciação GE et al. (2004). Como sua relação de $\mathrm{Ca} / \mathrm{P}$ é 1,67 e seus poros são relativamente pequenos, a HA apresenta um tempo maior de biodegradação que outros fosfatos de cálcio, o que foi observado na morfometria do tecido ósseo de coelhos em estudo realizado por AZEVEDO et al. (2012).

No presente trabalho, foi evidenciado que a associação da medula óssea com a quitosana promoveu aumento na diferenciação das células mesenquimais, porém as demais reações histológicas não diferiram muito daquelas observadas com o grupo QUI. Já a associação da MO com a HA apresentou apenas melhores resultados, comparado com a HA isolada. Esse fato pode ser explicado pela composição da $\mathrm{MO}$, que é rica em células mesenquimais indiferenciadas e fatores de crescimento, que atuam acelerando o processo de osteogênese (KRZYMANSKI et al., 1997).

Como observado na tabela 1 , aos 30 e 60 dias, os grupos QUI e QUIMO diferiram estatisticamente dos demais. Esse fato é explicado pelas características da quitosana de ser um biopolímero osteoindutor, que estimula a citodiferenciação, aumentando assim a deposição de matriz óssea (Figura 1). Outro fato relevante é que, mesmo não havendo diferença estatística entre a quitosana isolada e associada a MO, e também com
Tabela 1 - Média e desvio padrão da área em $\mu \mathrm{m}^{2}$ obtidos pela histomorfometria do tecido ósseo neoformado na interface osso/implante em coelhos, conforme o tipo de tratamento empregado e o período de avaliação.

\begin{tabular}{lll}
\hline $\begin{array}{l}\text { Grupos/ } \\
\text { Momentos }\end{array}$ & \multicolumn{1}{c}{30 dias } & \multicolumn{1}{c}{60 dias } \\
\hline HA & $52.527,3 \pm 29.733,2^{\mathrm{a}}$ & $56.587,6 \pm 16.742,0^{\mathrm{a}}$ \\
HAMO & $58.748,1 \pm 20.275,7^{\mathrm{a}}$ & $64.552,6 \pm 21.093,5^{\mathrm{a}}$ \\
QUI & $488.450,5 \pm 124.395,9^{\mathrm{b}}$ & $462.643,8 \pm 94.332,4^{\mathrm{b}}$ \\
QUIMO & $533.884,4 \pm 248.355,9^{\mathrm{b}}$ & $542.955,2 \pm 204.994,4^{\mathrm{b}}$ \\
\hline
\end{tabular}

HA = hidroxiapatita; HAMO = hidroxiapatita + medula óssea; QUI = quitosana; QUIMO = quitosana + medula óssea. Letras minúsculas diferentes na mesma coluna denotam diferença estatística $(\mathrm{P}<0,05)$.

a hidroxiapatita isolada e associada a MO, houve uma tendência de maior formação de tecido ósseo nos implantes que foram adicionados a MO. Esse fato pode ser explicado pela composição da MO que apresenta células mesenquimais indiferenciadas, com poder de diferenciação em osteoblastos e fatores de crescimento que estimulam a citodiferenciação e reparação tecidual (BRUDER \& FOX, 1999; WANG et al., 2002).

\section{CONCLUSÃO}

Conclui-se que os tratamentos empregados mostraram-se biocompatíveis. A quitosana isoladamente e em associação com medula óssea estimulara maior deposição de tecido ósseo tanto aos 30 como aos 60 dias, bem como estimulara reações celulares mais evidentes em coelhos.

\section{FONTES DE AQUISIÇÃO}

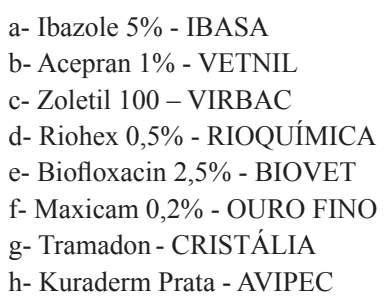

\section{COMITÊ DE ÉTICA E BIOSSEGURANÇA}

O presente estudo experimental foi aprovado pelo Comitê de Ética em Pesquisa da Unidade Acadêmica de Medicina Veterinária da Universidade Federal de Campina Grande (UAMV/ UFCG), segundo protocolo de aprovação no 100/2008. 


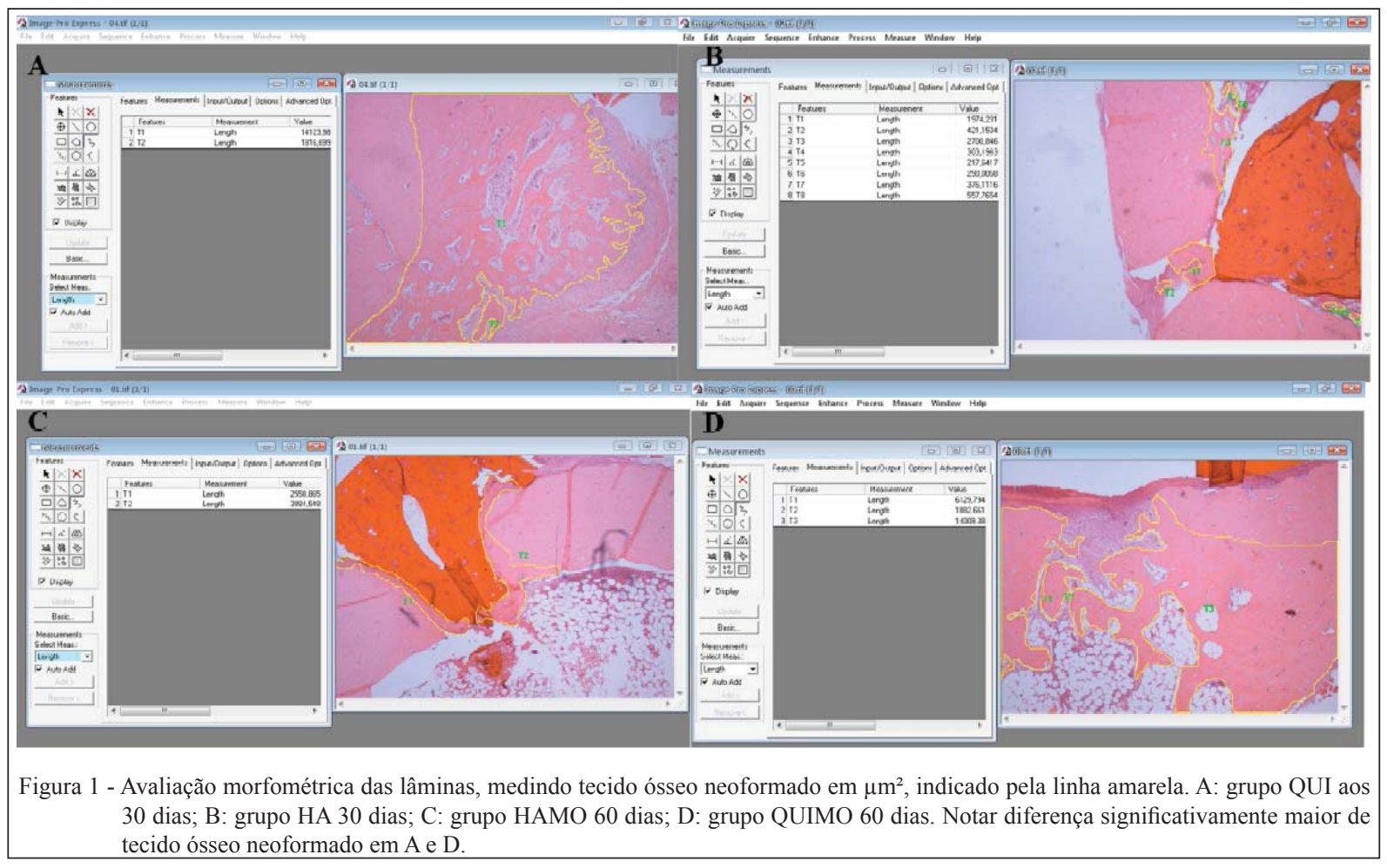

\section{REFERÊNCIAS}

ABUKAWA, $H$. et al. Formation of a mandibular condyle in vitro by tissue engineering. Journal of Oral and Maxillofacial Surgery, v.61, p.94-100, 2003. Disponível em: <http://www.joms. org/article/S0278-2391(02)15621-7>. Acesso em: 20 set. 2011. doi: $10.1053 /$ joms.2003.50015.

AZEVEDO, A.S. et al. Avaliação de diferentes proporções de fosfato de cálcio na regeneração do tecido ósseo de coelhos: estudo clínico-cirúrgico, radiológico e histológico. Brazilian Journal of Veterinary Research and Animal Science, v.49, p.12-18, 2012.

AZEVEDO, V.V.C. et al. Quitina e quitosana: aplicações como biomateriais. Revista Eletrônica de Materiais e Processos, v.23, p.27-34, 2007.

BRUDER, S.P.; FOX, B.S. Tissue engineering of bone. Cell based strategies. Clinical Orthopaedics and Related Research, v.367, p.68-83, 1999.

DOSS, M. et al. Embryonic stem cell: apromising tool for cell replacement therapy. Journal of Cellular and Molecular Medicine, v.8, p.465-473, 2004. Disponível em: <http:// onlinelibrary.wiley.com/doi/10.1111/j.1582-4934.2004.tb00471.x/ abstract>. Acesso em: 10 jul. 2011. doi: 10.1111/j.15824934.2004.tb00471.x.

GE, Z. et al. Hydroxyapatitechitin materials as potential tissue engineered bone substitutes. Biomaterials, v.25, p.1049-1058, 2004. Disponível em: <http://link.periodicos.capes.gov.br.ez15. periodicos.capes.gov.br/sfxlcl3>. Acesso em: 12 jul. 2011. doi: 10.1016/S0142-9612(03)00612-4.

GORZELANNY, C. et al. Human macrophage activation triggered by chitotriosidase-mediated chitin and chitosan degradation.
Biomaterials, v.31, p.8556-8563, 2010. Disponível em: $<$ http:// link.periodicos.capes.gov.br.ez15.periodicos.capes.gov.br/ sfxlc13?url_ver=Z39.88-2004>. Acesso em: 12 jul. 2011. doi: 10.1016/j.biomaterials.2010.07.100.

KHAN, T.A.; PEH, K.K. A preliminary investigation of chitosan film as dressing for punch biopsy wounds in rats. Journal of Pharmacy \& Pharmaceutical Sciences, v.6, p.20-26, 2003.

KHOR, E.; LIM, L.Y. Implantable applications of chitin and chitosan. Biomaterials, v.24, p.2339-2349, 2003. Disponível em: $<$ http://link.periodicos.capes.gov.br.ez15.periodicos.capes.gov. br/sfxlcl3?urlver=Z39.88-2004>. Acesso em: 14 ago. 2011. doi: 10.1016/S0142-9612(03)00026-7.

KRZYMANSKI, G. et al. The use of bone-marrowderived fibroblastoid cells and fresh bone marrow in the treatment of bone defects: an experimental study. International Journal of Oral and Maxillofacial Surgery, v.26, p.55-60, 1997.

LEGEROS, R.Z. Properties of osteoconductive biomaterials: calcium phosphates. Clinical Orthopaedics and Related Research, v.395, p.81-98, 2002.

LOPES, M.A. et al. Glass reinforced hydroxyapatite composites: secondary phase proportions and densification effects on bioactive bending strength. Journal of Biomedical Materials Research, v.48, p.734-740, 1999. Disponível em: <http://link. periodicos.capes.gov.br.ez15.periodicos.capes.gov.br/sfxlcl3?url ver $=Z 39.88-2004>$. Acesso em: 14 ago. 2011. doi: 10.1002/ (SICI)1097-4636(1999)48:5<734::AID-JBM20>3.0.CO;2-2.

MUZZARELI, R.A.A. et al. Stimulatory effect on bone formation exerted by a modified chitosan. Biomaterials, v.15. p.1075-1081, 1994. Disponível em: <http://link.periodicos.capes.gov.br.ez15. 
periodicos.capes.gov.br/sfxlc13?url_ver=Z39.88-2004>. Acesso em: 10 jul. 2011. doi: 10.1016/0142-9612(94)90093-0.

SHIMAKURA, Y. et al. Experimental study on bone formation potential of cryopreserved human bone marrow mesenchymal cell/ hydroxyapatite complex in the presence of recombin ant human bone morphogenetic protein-2. Journal of Craniofacial Surgery, v.14, p.108-116, 2003.

UENO, H. et al. Evaluation effects of chitosan for the extracellular matrix production by fibroblasts and the growth factors production by macrophages. Biomaterials, v.22, p.2125-2130, 2001. Disponível em: <http://link.periodicos.capes.gov.br.ez15.
periodicos.capes.gov.br/sfxlcl3?url_ver=Z39.88-2004>. Acesso em: 10 jul. 2011. doi: 10.1016/S0142-9612(00)00401-4.

WANG, X. et al. Bone repair in radii and tibias of rabbits with phosphorylated chitosan reinforced calcium phosphate cements. Biomaterials, v.23, p.4167-4176, 2002. Disponível em: $<$ http:// link.periodicos.capes.gov.br.ez15.periodicos.capes.gov.br/ sfxlc13?url_ver=Z39.88-2004>. Acesso em: 10 jul. 2011. doi: 10.1016/S0142-9612(02)00153-9.

ZAR, J.H. Biostatistical analysis. Upper Saddle River, New Jersey: Prentice Hall, 1999. 663p. 